\title{
Multiresponse optimization of turning process parameters using TOPSIS and finite element analysis simulation using DEFORM 2D
}

\author{
${ }^{1}$ Mohan Santhana Rajendiran and ${ }^{2}$ Dhanashekar Manickam \\ ${ }^{1}$ Assistant Professor, Department of Mechanical Engineering, Dhaanish Ahmed College of engineering, Chennai, India. \\ ${ }^{2}$ Research Scholar, Department of Mechanical Engineering, College of Engineering Guindy, Anna University, Chennai, India.
}

Correspondence Author: Dhanashekar Manickam, Research Scholar, Department of Mechanical Engineering, College of Engineering Guindy, Anna University, Chennai- 600025, India.

E-mail: dhanashekar.phd@gmail.com

Received date: 22 June 2018, Accepted date: 16 August 2018, Online date: 8 September 2018

Copyright: (C) 2018 Mohan Santhana Rajendiran and Dhanashekar Manickam. This is an open-access article distributed under the terms of the Creative Commons Attribution License, which permits unrestricted use, distribution, and reproduction in any medium, provided the original author and source are credited.

\begin{abstract}
Background: Manufacturing industries are widely dependent on the machining process to perform a specific job and one such important process is turning. Many researchers have divulged the importance of turning process under various forms such as tool selection, tool wear, tool life, minimum quantity lubrication, and machining parameters to curtail tool wear and dwindle surface roughness. Objective: This article discusses the experimental inquest of dry turning of AISI 1045 steel with tungsten carbide inserts (uncoated). TOPSIS method, best multiple attribute decision making method is employed to inquest the output quality factors namely chip temperature, tool-chip interface temperature, wear rate, wear depth and resultant forces. Results: The high values of cutting speed can be used only when the feed rate and cutting depth is minimum in order to obtain better surface texture. When the contact area of the tool cutting increases, the surface roughness of the machined surface increases due to the frictional heat generated, cutting force and temperature determines the surface texture. Conclusion: The Ci values were used to determine the contribution of machining parameters: feed rate was $44 \%$ and cutting speed was $31 \%$, which are the more influencing parameters than the depth of cut. DEFORM-2D software for tool wear analysis is performed for simulating the turning process under optimum conditions.
\end{abstract}

Key words: Turning process, TOPSIS, AISI 1045 steel, Tool wear.

\section{INTRODUCTION}

Turning process is inevitable in any industry and the selection of proper tool and machining conditions are the concern. Dry machining is where the machining is carried out in the absence of any coolant and the various advantages are no pollution in the atmosphere, no residue left on the workpiece and cleaning cost spent to remove it, no health danger to the operator, free from allergic to the skin. Knowledge of material removal concepts in the machining process is very important for engineers before designing a part/component. The key tool failures occurring in hard turning process are flank wear, crater wear, notching wear, chipping, plastic deformation due to temperature, etc. Experimental and analytical methods are available to investigate the type of tool wear occurring in hard turning.

Many researchers have conducted various machining studies on AISI 1045 steel and used FEM to estimate tool wear using wear characteristics equation and the highlights are discussed as follows. Ashwin Devotta et al [1], have conducted FEM to predict the effect of rake angle on chip segmentation in machining AISI 1045 steel. Oscar Velásquez Arriaza et al [2], have made an experimental study on milling AISI 1045 steel where the tool life is predicted by measuring the tool wear at periods. Young Ho Choi et al [3] have performed Induction Assisted Machining (IAM) on AISI 1045 steel and results showed that IAM had better surface finish than the conventional machining. The feed rate highly influenced the chip formation. Radoslaw W. Maruda et al [4] have investigated the machining of AISI 1045 steel with Lubrication and dry turning process for changes in structure and microhardness and the results showed that lubrication had reduced the hardening effect by $40 \%$ when compared to dry machining. Sung and Choon [5] have utilized the Thermal Assisted Machining (TAM) types such as Laser assisted Milling (LAMill) and Plasma Assisted Machining (PAM) methods in machining AISI 1045 steel. They found that PAM had better surface quality and reduced cutting force when compared to other LAMill and Conventional machining. Mohammad Nizamuddin et al [6] have used Karanja oil mixed in cutting fluid for orthogonal machining of AISI 1045 steel and $11 \%$ reduction in chip thickness and tool life was improved. Zhang and Wu [7] have experimented hard turning of AISI 1045 steel using a PCBN tool with designed chip breaker grooves for analyzing the various chip formation at micro and macro level and the results showed that proper selection of feed rate and cutting depth assisted with high speed turning can produce desirable surface finish.

Ersan Aslan et al [8] have optimized the machining parameters while machining AISI 4140 steel with $\mathrm{Al}_{2} \mathrm{O}_{3}$ based ceramic tool and cutting speed -feed rate and feed rate - depth of cut interactions have influenced the surface roughness. Jaharah et al [9] have studied turning of AISI 1045 steel with uncoated carbide tool. They found that the cutting speed contributed 52.1\%, rake angle of $40.59 \%$, feed rate of 5.85\% and clearance angle of $1.46 \%$. Nalbant et al [10] have optimized the turning process parameters for AISI 1030 carbon steel using Taguchi method and the results showed that higher insert radius, low feed rate and minimum cutting depth to dwindle surface roughness. Iqbal et al [11] have studied the machining of AISI 1045 steel by considering different rake face friction and observed that reduced chip compression ratios lead to curtail tool-chip interface contact and chip thickness. Yung Chang Yen et al [12] have shown that how various tool geometries like round/hone edge and chamber edge affects process variables while machining AISI 1020 by carbide tool (uncoated). Sayyed siraj et al [13], have 
performed hard turning AISI 52100 steel by varying nose radius of the cutting tool and revealed that nose radius affects the surface roughness. Sanchit Kumar Khare et al [14], have conducted the machining of AISI 4340 steel and optimized process parameters for minimum surface roughness and they observed that cutting speed and cutting depth was the most contributing factors.

From the literature it is evident that optimizing machining parameters and analysis of tool wear using FEA was investigated only by few researchers. This paper aims to examine the turning of AISI 1045 steel using uncoated tungsten carbide tool and TOPSIS method to optimize the turning parameters: cutting speed, feed rate and cutting depth for the output responses: chip temperature, tool chip interface temperature, wear rate, wear depth and cutting forces. DEFORM-2D, Finite element analysis software is used to simulate the turning process, which is based on the Lagrangian equation. DEFORM-2D is used to simulate the turning process for various machining parameters while turning the AISI 1045 using uncoated cemented carbide tool.

\section{MATERIALS AND METHOD}

AISI 1045 carbon steel is selected as base material for hard turning process and metal cutting simulation. Its chemical composition is C-0.43\%, Mn-0.6$0.9 \%, \mathrm{P}-0.04 \% \max , \mathrm{S}-0.05 \%$, Si-(0.15-0.3\%), Fe- $98.4 \%$. It is an alloy with adequate strength and toughness with wide applications including shafts, pins, bolts, structural element, and gears. The cutting tool insert material was uncoated Tungsten carbide. The controlling process variables are cutting speed, feed rate and cutting depth and a broadly preferred Taguchi experimental design [2], L9 orthogonal array with 9 experiments are considered for optimization. The details of turning process parameters and its levels are given in table.1. The cutting speed was limited within $367 \mathrm{~m} / \mathrm{min}$ as higher speed induces structural changes due to dynamic recrystallization [4].

Table 1: Input process Parameters and its levels.

\begin{tabular}{|l|l|l|l|l|}
\hline SI. No & Parameter/Level & Level 1 & Level 2 & Level 3 \\
\hline 1 & Cutting speed $(\mathrm{m} / \mathrm{min})$ & 227 & 256 & 285 \\
\hline 2 & Feed rate $(\mathrm{mm} / \mathrm{rev})$ & 0.432 & 0.318 & 0.203 \\
\hline 3 & Depth of cut $(\mathrm{mm})$ & 0.3 & 0.45 & 0.6 \\
\hline
\end{tabular}

The experimental design of turning process is given in table.2. The output response considered were chip temperature, tool chip interface temperature, wear rate, wear depth and cutting forces. Steps involved in TOPSIS method for optimizing the turning parameters are given below:

Step 1: Calculate the normalized performance matrix $\mathrm{r}_{\mathrm{ij}}$ using equ.1.

$\mathrm{r}_{i j}=\frac{x_{i j}}{\sqrt{\sum_{j=1}^{n} x_{i j}}}$

$$
(i=1,2,3, . ., m ; j=1,2,3, \ldots, n)
$$

Step 2: Provide weight to this matrix by using equ.2.

$$
v_{i j}=w_{i} \times r_{i j} \quad(\mathrm{i}=1,2,3, \ldots, \mathrm{m} ; \mathrm{j}=1,2,3, \ldots, \mathrm{n})
$$

Step 3: Define the best ideal solution and nadir ideal solution as follows

$A^{+}=\left\{v_{1}^{+}, v_{2}^{+}, \ldots . ., v_{n}^{+}\right\}=\left\{\left(\max _{j} v_{i j} \mid i \in I^{v}\right),\left(\min _{j} v_{i j} \mid i \in I^{n}\right)\right\}$

$\mathrm{i}=1,2,3, . ., \mathrm{m}, \mathrm{j}=1,2,3, \ldots, \mathrm{n}$

$A^{-}=\left\{v_{1}^{-}, v_{2}^{-}, \ldots \ldots, v_{n}^{-}\right\}=\left\{\left(\min _{j} v_{i j} \mid i \in I^{v}\right),\left(\max _{j} v_{i j} \mid i \in I^{n}\right)\right\}$

$\mathrm{i}=1,2,3, . ., \mathrm{m}, \mathrm{j}=1,2,3, \ldots, \mathrm{n}$

$I_{\text {where; }} I^{y}$ is related to benefit attributes and $I^{n V}$

Step 4: In this step the values of $D_{i}^{+}$and $D_{i}^{-}$were determined using the equations given below $(5,6)$

$D_{i}^{+}=\sqrt{\sum_{j=1}^{n}\left(v_{i j}-v_{j}^{+}\right)^{2}}$

$D_{i}^{-}=\sqrt{\sum_{j=1}^{n}\left(v_{i j}-v_{j}^{-}\right)^{2}}$

$$
\mathrm{i}=1,2, \ldots ., \mathrm{m}
$$

Step 5: For each alternative closeness coefficient values were determined using the equ.7

$C_{i}=\frac{D_{i}^{-}}{D_{i}^{-}+D_{i}^{+}}$

$\mathrm{i}=1,2, \ldots, \mathrm{m}$

The best alternative was chosen according to preference ranking ordered by the $\mathrm{C}_{\mathrm{i}}$ value, which is very close to the ideal solution.

Simulation process is carried out by changing the cutting speed, feed rate and depth of cut. Initial temperature for the work material and the cutting tool is set at $30{ }^{\circ} \mathrm{C}$ (room temperature). Simulation is carried initially considering transient condition and then transferred out to reach steady state condition. Tool stress analysis is performed to obtain stress data on the cutting tool. Cutting tool is modeled and considered as elastic and the resultant force acting on the tool edge is generated by interpolating the force on the cutting tool. The cutting tool mesh and workpiece mesh is shown in Fig. (1 and 2) respectively. Usui's tool wear model given in equ.8, where the applied pressure, relative velocity and absolute temperature at the contact surface are considered as a wear rate function with the constants having the values were $\mathrm{A}=7.8 \times 10^{-9}$ and $\mathrm{B}=5302$.

\section{$\frac{a W}{d t}=A \sigma_{n} V_{s} \exp \left(-B_{T}\right)$}

(A, B are Constants) 


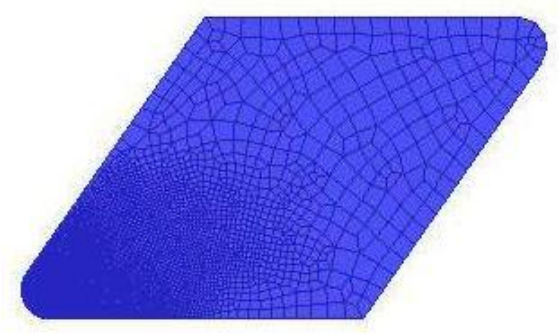

Fig. 1: Cutting tool mesh.

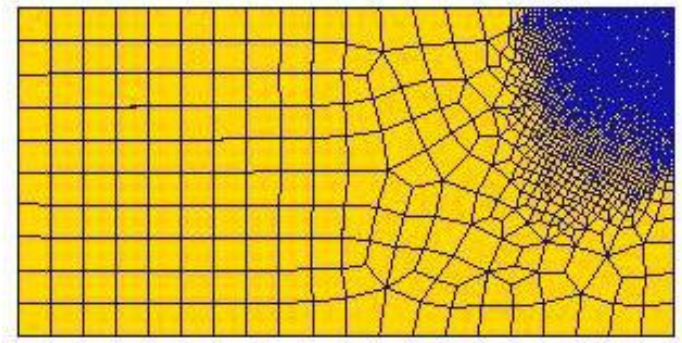

Fig. 2: Workpiece mesh.

\section{RESULTS AND DISCUSSION}

Based on $\mathrm{L}_{9}$ Orthogonal array designed using Taguchi's design of experiments machining were conducted to examine the effects of different machining parameters considered. After conducting the dry turning process, output characteristics like Chip temperature, tool chip interface temperature, wear rate, wear depth and resultant cutting forces were determined, which are tabulated and the normalized values computed using equ.1 is given in table 2 . For all the output responses equal weightage (0.5) was given and then weighted normalized matrix were determined using the equ.2. The next step is to compute the best and worst alternative performance. This was computed using the equ. $(3,4)$ and the values are: $\mathrm{A}^{+} \max (376.33810,236.49056,0.000455,0.002996,258.8065)$ and $\mathrm{A}^{-}$min $(165.47727,131.46968,4.66427 \mathrm{E}-05,0.0013857,160.29146)$. The next step was to determine the best alternative distance $D_{i}^{+}$and the worst alternative distance $D_{i}^{-}$

using the equ. $(5,6)$. Equ.7 is used to compute the closeness coefficient values for every alternatives and the raking is given in table.3. From table.3, Exp. No. 3 showed the best multiresponse characteristics. The experiment is closer to the ideal solution when the $\mathrm{C}_{\mathrm{i}}$ value is maximum. For Exp. No. 3, the input parameter levels are: cutting speed $227 \mathrm{~m} / \mathrm{min}$, feed rate $0.203 \mathrm{~mm} / \mathrm{rev}$, and depth of cut $0.6 \mathrm{~mm}$ yielded the optimal performance. The average closeness coefficient values are computed and given in table.4. Fig.3 shows the main effect plot for $\mathrm{C}_{\mathrm{i}}$ Closeness coefficient values and it is observed that optimal processing conditions are cutting speed $227 \mathrm{~m} / \mathrm{min}$, feed rate $0.203 \mathrm{~mm} / \mathrm{min}$, depth of cut $0.45 \mathrm{~mm}$. Feed rate is the most effective process parameter as its max-min value is higher than that of the other input parameters. The surface finish is more sensitive to feed rate [7], lower values of feed rate produces better surface finish.

Table 2: Design of experiments and normalized values of output responses.

\begin{tabular}{|l|l|l|l|l|l|l|l|l|}
\hline $\begin{array}{l}\text { Ex. } \\
\text { No. }\end{array}$ & Cutting speed & Feed rate & $\begin{array}{l}\text { Depth of } \\
\text { cut }\end{array}$ & Chip Temperature & $\begin{array}{l}\text { Tool-Chip } \\
\text { Interface } \\
\text { Temperature }\end{array}$ & wear rate & Wear Depth & Resultant Force \\
\cline { 2 - 9 } & $(\mathrm{m} / \mathrm{min})$ & $(\mathrm{mm} / \mathrm{rev})$ & $(\mathrm{mm})$ & $\left({ }^{\circ} \mathrm{C}\right)$ & $\mathrm{mm} / \mathrm{sec})$ & $\mu \mathrm{m}$ & $(\mathrm{N})$ \\
\hline 1 & 227 & 0.432 & 0.3 & 557.9262 & 372.9664 & 0.00026 & 0.004365 & 511.5118 \\
\hline 2 & 227 & 0.318 & 0.45 & 330.9545 & 262.9394 & $9.33 \mathrm{E}-05$ & 0.003585 & 401.3809 \\
\hline 3 & 227 & 0.203 & 0.6 & 375.0359 & 289.5353 & 0.000144 & 0.002772 & 331.7972 \\
\hline 4 & 256 & 0.432 & 0.45 & 571.8738 & 414.3769 & 0.000458 & 0.004365 & 497.1856 \\
\hline 5 & 256 & 0.318 & 0.6 & 517.1165 & 379.7168 & 0.000411 & 0.004162 & 416.3813 \\
\hline 6 & 256 & 0.203 & 0.3 & 386.4867 & 267.4727 & 0.000125 & 0.003836 & 323.7211 \\
\hline 7 & 285 & 0.432 & 0.6 & 752.6762 & 472.9811 & 0.00091 & 0.003165 & 517.613 \\
\hline 8 & 285 & 0.318 & 0.3 & 636.7689 & 443.1947 & 0.000854 & 0.005994 & 424.9543 \\
\hline 9 & 285 & 0.203 & 0.45 & 517.1165 & 400.3312 & 0.000669 & 0.005296 & 320.5829 \\
\hline
\end{tabular}

The second influencing parameter is cutting speed and the higher cutting speed needs to choose only at lower values of depth of cut [7] else it leads to increase in surface roughness due to interface temperature. The depth of cut is the least influencing parameters. The increase in cutting speed will lead to the premature tool wear and cause tool chatter [2]. The \% contribution of each process parameters is represented in Fig.4. These results agree well with the previous research findings $[9,12]$. Higher values of feed rate result in maximum chip temperature, tool chip interface temperature, wear rate, wear depth and cutting force. The resultant force applied on the tool increases with the increase in feed rate.

Table 3: Closeness coefficient values and ranking of alternatives.

\begin{tabular}{|l|l|l|l|l|}
\hline Ex. No & $D_{i}^{+}$ & $D_{i}^{-}$ & $C_{i}$ & Ranking \\
\hline 1 & 158.1739 & 109.5077 & 0.409097 & 6 \\
\hline 2 & 40.399 & 242.6297 & 0.857262 & 3 \\
\hline 3 & 26.34515 & 229.5605 & 0.897051 & 1 \\
\hline 4 & 167.4544 & 95.57884 & 0.363372 & 7 \\
\hline 5 & 119.8651 & 136.4134 & 0.532286 & 5 \\
\hline 6 & 27.90261 & 231.2588 & 0.892335 & 2 \\
\hline 7 & 255.3368 & 0.001414 & $5.54 \mathrm{E}-06$ & 9 \\
\hline 8 & 185.0053 & 75.6759 & 0.290301 & 8 \\
\hline 9 & 115.6858 & 157.7872 & 0.576976 & 4 \\
\hline
\end{tabular}


Table 4: Average closeness coefficient values.

\begin{tabular}{|l|l|l|l|}
\hline Levels/ Process parameters & Cutting speed & Feed rate & Depth of cut \\
\hline Level 1 & 0.72114 & 0.25749 & 0.53058 \\
\hline Level 2 & 0.596 & 0.55995 & 0.5992 \\
\hline Level 3 & 0.28909 & 0.78879 & 0.47645 \\
\hline Max - Min & 0.432043 & 0.531296 & 0.122755 \\
\hline
\end{tabular}

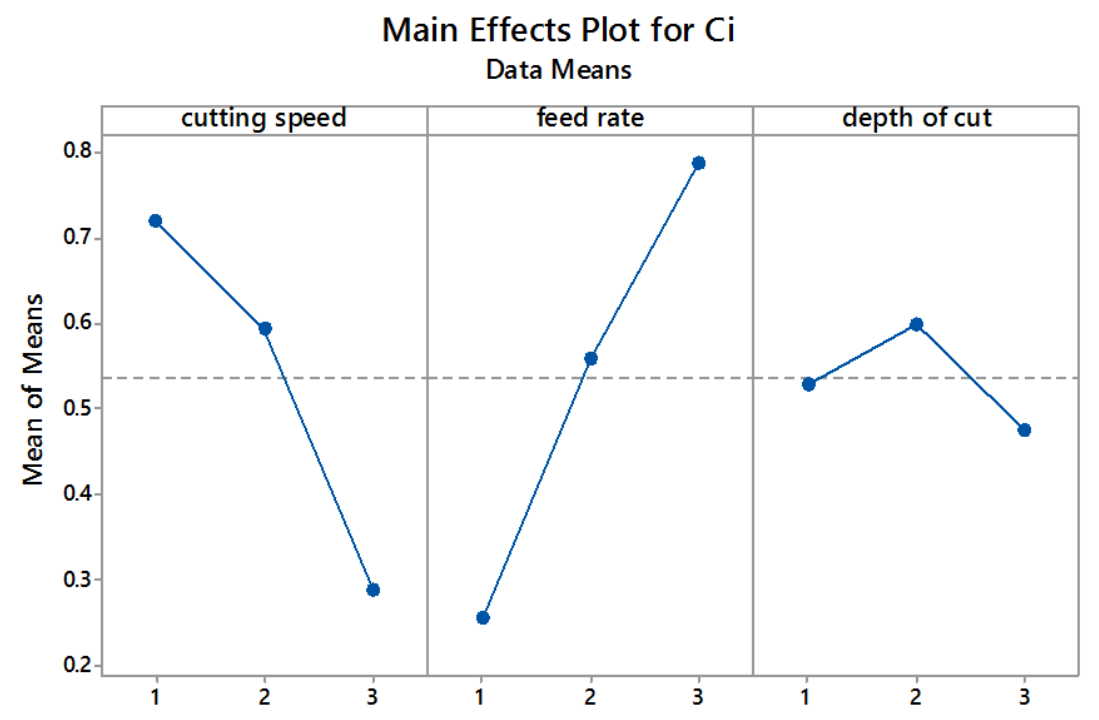

Fig. 3: Main effect plot for the closeness coefficient value.

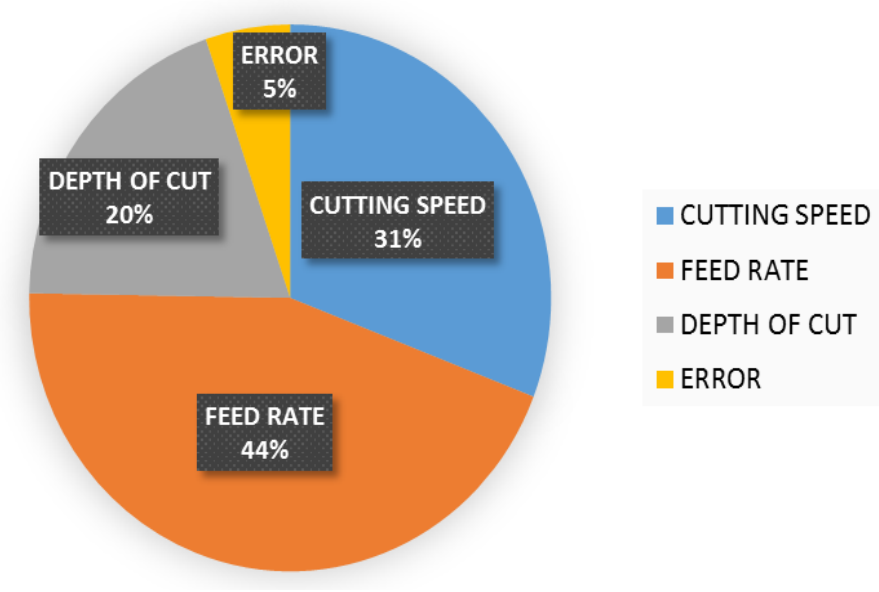

Fig. 4: Contribution chart for the hard turning parameters.

From the table.4, the optimum process variables that were identified are cutting speed as ' $227 \mathrm{~m} / \mathrm{min}$ ', feed rate as ' $0.203 \mathrm{~mm} / \mathrm{rev}$ ', and cutting depth as ' 0.45 $\mathrm{mm}$ '. With these optimum parameters, a simulation analysis is conducted and quality characteristics were determined. Chip temperature is $1370{ }^{\circ} \mathrm{C}$, Tool-chip interface temperature of $1020{ }^{\circ} \mathrm{C}$, wear rate of $0.00088 \mathrm{~mm} / \mathrm{sec}$, wear depth of $0.0000104 \mathrm{~mm}$ and resultant cutting force of $1129.43 \mathrm{~N}$. The Fig. (5 and 6) shows the model generated having chip produced while turning with optimum machining parameters and the distribution of cutting forces on the cutting tool respectively.

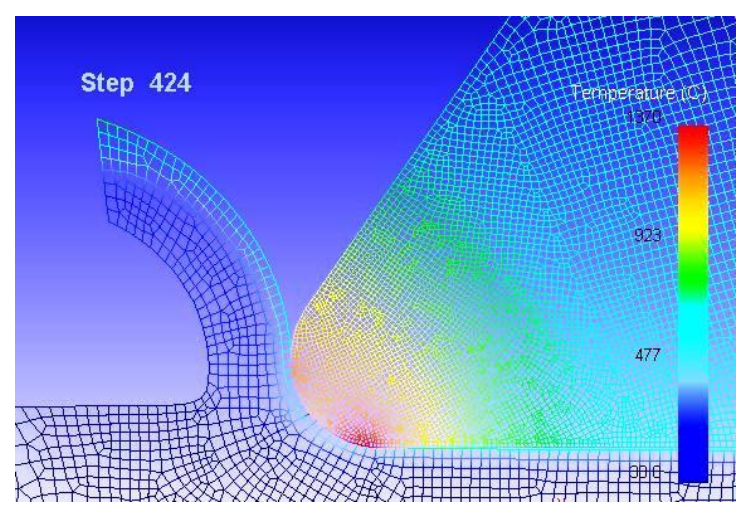

Fig. 5: Simulation Result of Optimum Tool Condition. 


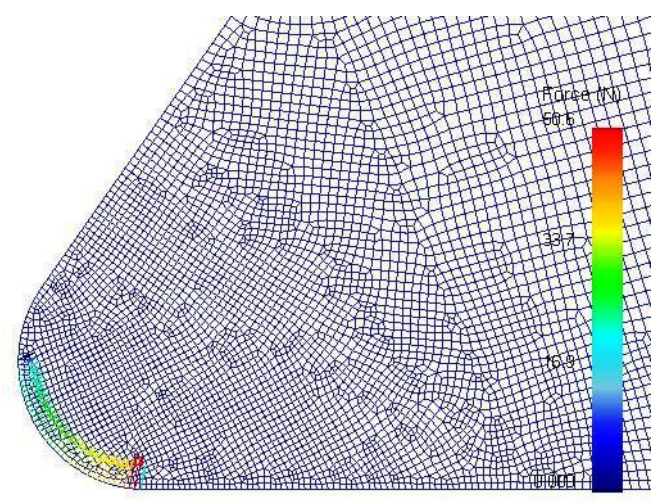

Fig. 6: Distribution of cutting forces at Optimum Cutting conditions.

\section{Conclusion:}

TOPSIS method was used to optimize the machining parameters and also using finite element analysis while turning AISI 1045 steel by uncoated carbide cutting tool insert. Simulation results obtained from the finite element analysis software DEFORM-2D, it is concluded that,

1. The TOPSIS method was effective in solving the multi criteria decision making in identifying the optimal turning process parameters.

2. The optimum machining parameters obtained using TOPSIS method were cutting speed at $227 \mathrm{~m} / \mathrm{min}$, feed rate at $0.203 \mathrm{~mm} / \mathrm{rev}$ and cutting depth at 0.45 $\mathrm{mm}$.

3. As the cutting speed increases, the chip temperatures, tool-chip interface temperature, wear depth, wear rate increases.

4. As the cutting depth varies, the tool-chip interface temperature varies marginally and for lower depth of cut, the wear depth is less and the cutting forces were moderate.

5. For high speed machining the feed rate should be minimum.

6. Hence it is concluded that for a moderate tool-chip interface temperature and tool wear the turning process should done at lower cutting speed and lower feed rate.

5. Future Work:

1. By considering the various cutting tool rake angle, we can estimate the tool life in machining AISI 1045 steel based on chip formation.

2. Further, computational analysis for the flank wear performance run under thermal condition using DEFORM 3D software.

\section{REFERENCES}

[1] Ashwin Devotta, Tomas Beno, Raveendra Siriki, Ronnie, Mahdi Eynian, 2017. Finite element modelling and validation of chip segmentation in machining of AISI 1045 steel. Procedia CIRP, 58: 499-504.

[2] Oscar Velasquez Arriaza, Basmir Cuka, Jong-Young Lee, Dong-Won Kim, 2017. Energy Usage Analysis of Carbide and Mills on AISI 1045 Steel. Procedia Manufacturing, 11: 734-741.

[3] Young Ho Choi, Choon Man Lee, 2018. A study on the machining characteristics of AISI 1045 steel and with circular cone shape in induction assisted machining. Journal of Manufacturing Processes, 34: 463-476.

[4] Radoslaw W. Maruda, Grzegorz M. Krolczyk, Mariusz Michalski, Piotr Nieslony, 2016. Structural and Microhardness Changes After Turning of the AISI 1045 Steel for Minimum Quantity Cooling Lubrication. Journal of Materials Engineering and Performance, 26(1): 431-438.

[5] Sung-Ho Moon., Choon-Man Lee, 2018. A study on the machining characteristics using plasma assisted machining of AISI 1045 steel and Inconel 718. International Journal of Mechanical Sciences, 142-143: 595-602.

[6] Mohammad Nizamuddin, Sachin M. Agrawal, Nilesh Patil, 2018. The Effect of Karanja based Soluble Cutting Fluid on Chips Formation in Orthogonal Cutting Process of AISI 1045 Steel. Procedia Manufacturing, 20: 12-17.

[7] Zhang, X.P., S.B. Wu, 2016. Chip control in the dry machining of hardened AISI 1045 steel. International Journal of Advanced Manufacturing Technology, 88(9-12): 3319-3327.

[8] Erasan Aslan, Neeip Camuscu, Burak Birgoran, 2007. Design optimization of cutting parameters when turning hardened $\mathrm{AISI} 4140(63 \mathrm{HRC})$ with $\mathrm{Al}_{2} \mathrm{O}_{3}+$ TiCN mixed ceramic tool. International Journal of Materials and Design, 28(5): 1618-1622.

[9] Jaharah, A.G., S.W. Wahid, C.H. Che Hassan, M.Z. Nuawi, MohdNizan Ab Rahman, 2009. The effect of uncoated carbide tool geometries in turning AISI 1045 using finite element analysis. European Journal of Scientific Research, 28(2): 271-277.

[10] Nalbant, M., H. Gokkaya, G. Sur, 2007. Application of Taguchi method in the optimization of cutting parameters for surface roughness in turning. International Journal of Materials and Design, 28(4): 1379-1385.

[11] Iqbal, S.A., P.T. Mativenga, M.A. Sheikh, 2007. Characterization of machining of AISI 1045 steel over a wide range of cutting speeds. Part 1: Investigation of contact phenomena. Proceedings of the Institution of Mechanical Engineers, Part B: Journal of Engineering Manufacture, 221(5): 917-926.

[12] Yung-Chang Yen, Anurag Jain, Taylan Akhan, 2004. A finite element analysis of orthogonal machining using different tool edge geometries. Journal of Materials Processing Technology, 146(1): 72-81.

[13] Sayyed Siraj, H.M. Dharmadhikari, Nilesh Gore, 2018. Modelling of roughness value from tribological parameters in Hard turning of AISI 52100 steel. Procedia Manufacturing, 20(1): 344-349.

[14] Sanchit Kumar Khare, Sanjay Agarwal, 2017. Optimization of Machining Parameters in Turning of AISI 4340 Steel under Cryogenic Condition Using Taguchi Technique. Procedia CIRP. 63(1): 610-614. 